\title{
Unusual presentation of uterine rupture following laparoscopic myomectomy: a case report and literature review
}

\author{
Cassandra P. S. Cheong*, Andy W.K. Tan, Lay Kok Tan, Su Ling Yu
}

Department of Obstetrics and Gynecology, Singapore General Hospital, Singapore

Received: 02 March 2018

Accepted: 07 March 2018

\section{*Correspondence:}

Dr. Cassandra P.S. Cheong,

E-mail: cassandra.cheong@mohh.com.sg

Copyright: ( $)$ the author(s), publisher and licensee Medip Academy. This is an open-access article distributed under the terms of the Creative Commons Attribution Non-Commercial License, which permits unrestricted non-commercial use, distribution, and reproduction in any medium, provided the original work is properly cited.

\begin{abstract}
Laparoscopic myomectomy is preferred to the laparotomy approach as the former promises a better postoperative course, with fewer complications and faster recovery. It is increasingly performed in younger women in recent years. However, although rare, uterine rupture is an important and dangerous complication. Authors report a case of 36-yearold lady who presented at 23 weeks and 4 days gestation of an in vitro fertilization (IVF) dichorionic diamniotic twin pregnancy with spontaneous uterine rupture. She underwent a laparoscopic myomectomy three year prior for a $4.5 \mathrm{~cm}$ fundal fibroid. Her presenting symptoms include acute onset of epigastric pain. Uterine rupture was confirmed using Computed Tomography scan. She underwent an exploratory laparotomy and the placenta was found extruding from a $4 \mathrm{~cm}$ defect on the posterior fundus along the previous myomectomy scar with active bleeding. Current literature suggests it is difficult to predict when uterine rupture may happen. Proper selection criteria for suitable cases may allow trial of labour after myomectomy to be a viable option. Potential considerations include interval between myomectomy and conception, scar integrity, method of repair, and the use of electrocoagulation. This case reports the worrying features of an early antepartum rupture presenting with atypical symptomatology. In pregnant patients presenting with abdominal pain or haemodynamic instability, it is imperative to consider uterine rupture so as to perform timely intervention. Those with a history of laparoscopic myomectomy should be considered high risk and counseled about the risk of rupture with extensive discussion about mode of delivery.
\end{abstract}

Keywords: Abdominal pain, Electrocoagulation, In vitro fertilization, Laparoscopy, Myomectomy, Multiple Pregnancy, Trial of labour, Uterine rupture, Uterine scar

\section{INTRODUCTION}

With the increasing age of conception and prevalence of fibroids, which occurs in $70 \%$ of woman by age 50 , myomectomy is a frequent intervention in women who wish to preserve their fertility. ${ }^{1}$

Laparoscopic myomectomy is recognized as preferable to the laparotomy approach as the former promises a better postoperative course, with fewer complications and faster recovery. ${ }^{1}$ Myomectomy has also been shown to improve reproductive performance in women with subfertility or pregnancy losses. ${ }^{2}$ As a result, laparoscopic myomectomy is increasingly performed in younger women. Though rare, an important and dangerous complication of laparoscopic myomectomy is uterine rupture.

Uterine rupture is an obstetric emergency that has serious maternal and fetal morbidity and mortality. A systematic review reported the rate of uterine rupture to be $0.49 \%$ after laparoscopic myomectomy, in comparison to $0.02 \%$ in an unscarred uterus. ${ }^{3,4}$

Authors detail a case of spontaneous uterine rupture at 23 weeks and 4 days in an in vitro fertilization twin pregnancy with a history of laparoscopic myomectomy. 


\section{CASE REPORT}

Studied patient was a 36-year-old Chinese lady who presented to the labour suite with acute onset of constant abdominal pain at 23 weeks and 4 days gestation. This was an in vitro fertilization (IVF) pregnancy resulting in a dichorionic diamniotic twin pregnancy. Prior to admission, her antenatal progress had been uneventful. Her past medical history involved a laparoscopic myomectomy three years prior for a $4.5 \mathrm{~cm}$ fundal fibroid in private hospital. She also had 2 previous unsuccessful IVF attempts over the past two years leading up to this pregnancy.

Initial examination revealed mild tenderness in the epigastric region with a soft abdomen. There was no rebound or guarding. Fetal heart sounds were heard on doppler. She was admitted to the delivery suite for close monitoring with an initial clinical impression of gastroenteritis in pregnancy. Despite symptomatic relief, her pain worsened. An urgent ultrasound was performed. The cervical length was $1.7 \mathrm{~cm}$ with funneling and incidental finding of a 7.7 × 5.7 × $3.8 \mathrm{~cm}$ cystic mass containing low-level echoes and an echogenic area posterior to the cervix in the pouch of Douglas suspicious for collection of blood clots.

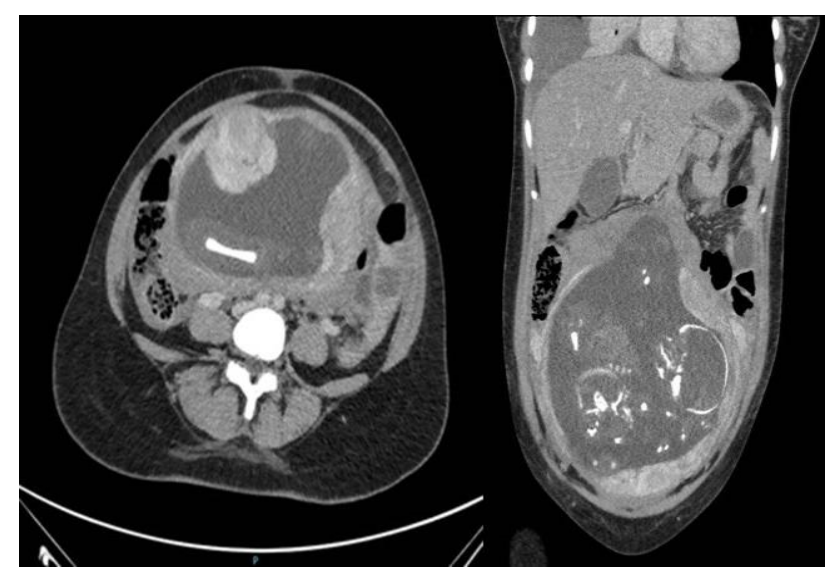

Figure 1: Computed Tomography of the Abdomen and Pelvis showing dehiscence at the uterine fundus measuring $5.3 \times 5.7 \times 4.5 \mathrm{~cm}$.

The pain intensified, and she became hemodynamically unstable with maternal tachycardia of recorded heart rate from 106 to $119 \mathrm{bpm}$. Her haemoglobin levels fell from 11.3 to 8.2 to $7.4 \mathrm{~g} / \mathrm{dL}$ and blood transfusion was initiated. Subsequently, she complained of contraction pain with vaginal bleeding. Speculum examination showed a pool of blood stained liquor. The impression was intra-abdominal bleeding with possible preterm premature ruptured of membranes (PPROM). An urgent surgical opinion was sought. The patient consented for an urgent Computed Tomography (CT) of the abdomen and pelvis to rule out possibility of splenic artery aneurysm. This revealed dehiscence of the uterine fundus measuring $5.3 \times 5.7 \times 4.5 \mathrm{~cm}$ with adjacent hematoma and moderate hemoperitoneum (Figure 1), and a moderate right-sided pleural effusion (Figure 2) which was further evaluated with CT Thorax.

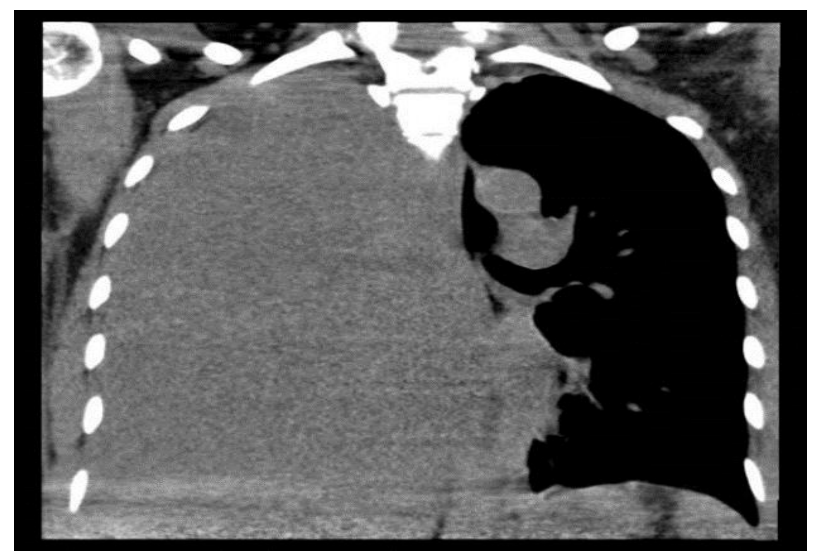

Figure 2: Computed tomography of the chest showing right hemothorax

In view of the borderline viability of the twins, couple received intensive counselling from the neonatologists on the fetal morbidity and mortality. Couple decided for active management on the twins. Preoperatively, a rightsided chest tube was inserted which subsequently drained $700 \mathrm{ml}$ of haemoserous fluid. An exploratory midline laparotomy was done. The placenta was found extruding from a $4 \mathrm{~cm}$ defect on the posterior fundus along the previous myomectomy scar, with active bleeding noted. The uterus was exteriorized, and a classical caesarean section performed, delivering both babies en caul. Multiple modified B-lynch sutures were applied to the lower segment of the uterus together with uterine arteries ligation. The uterus was closed with herring-bone closure in 3 layers followed by B lynch compression suture.

Postoperatively, she was admitted to the Surgical Intensive Care Unit. Her condition improved steadily. The chest tube was removed subsequently. Patient made a good recovery and was discharged well on postoperative day 10 .

Both twins were admitted to the Neonatal Intensive Care Unit on ventilator support with Twin 1 weighing $578 \mathrm{~g}$ and Twin $2560 \mathrm{~g}$. However, the twins subsequently died on day 5 and day 12 of life respectively due to extreme prematurity.

\section{DISCUSSION}

The prevalence of fibroids is 70 to $80 \%$ by the age of $50{ }^{1}$ In most cases, these fibroids remain asymptomatic. However, an indication for myomectomy in women of reproductive age would be pregnancy losses after exclusion of other causes. A retrospective study revealed that pregnancy loss reduced from $60 \%$ to $24 \%$ following myomectomy. ${ }^{2}$ Laparoscopic myomectomy is commonly associated with shorter recovery time, fewer surgical 
complications. ${ }^{5}$ There is also less adhesion formation, which is of particular importance where pregnancy is still desired. ${ }^{6}$ However, a particular controversy surrounding laparoscopic myomectomy is the strength and integrity of its scar compared to that of laparotomy myomectomy during subsequent pregnancies. Case reports of uterine rupture after laparoscopic myomectomy have raised doubts regarding the safety of this approach. ${ }^{7-11}$ A recent systematic review analyzed 23 studies on 2367 pregnancies after myomectomy and found the overall incidence of uterine rupture to be $0.6 \%$. Of these, the incidence of uterine rupture after laparotomy myomectomy was $0.67 \%$ compared to $0.99 \%$ of that after the laparoscopic approach. ${ }^{3}$

A review of current literature suggests that to date, it is difficult to predict when uterine rupture may happen - it can happen anytime under any circumstance. The gestation age of these case reports extends from midtrimester to the third trimester. ${ }^{7,8,10}$ A systematic review compared antepartum and intrapartum uterine rupture and demonstrated that it was $1.52 \%$ and $0.47 \%$ respectively. This was however not statistically significant. ${ }^{3}$ The lower incidence of intrapartum uterine rupture could possibly be due to most women having already undergone an elective caesarean delivery prior to the onset of labor. Nevertheless, a rupture rate of $0.47 \%$ in women undergoing trial of labor with previous myomectomy is comparable to that of $0.5 \%$ in women with previous caesarean section. ${ }^{4}$ This suggests that, with careful selection, trial of labour after myomectomy could possibly be an equally viable option as with VBAC. However, this would require validation with larger prospective studies. Proper selection criteria for suitable cases should also be created.

In order to adequately create such a selection criterion, many studies have sought to identify possible risk factors for uterine rupture to better guide future practices. The followings are few important considerations.

\section{Interval after laparoscopic myomectomy for conception}

When after laparoscopic myomectomy then is it safe for conception? There is no consensus with regards to the interval before it is safe for pregnancy. Some centers advise women to wait at least 12 months for healing of uterine scars before attempting to conceive. ${ }^{12}$ While this makes theoretical sense, the rate of healing is different in every case. Factors include patient's comorbidities influencing one's healing potential, location of myoma excised, whether the endometrium was breached, number of myoma removed etc. More often than not, in clinical practice, this advice is based on obstetrician's experience and clinical judgment. There has also been a case report of a successful uncomplicated pregnancy conceived 10 months after laparoscopic myomectomy, before a uterine rupture in the next pregnancy. ${ }^{10}$ Likewise, in Tian's retrospective study, a defective scar was found during elective caesarean section of a patient whose pregnancy interval was 33 months. ${ }^{13}$ These varied examples suggest that there is unlikely any conclusive relation between risk of uterine rupture and pregnancy interval.

\section{Assessment of scar integrity}

Some centers suggest a second look laparoscopy after laparoscopic myomectomy to determine wound healing. A retrospective study by Kumakiri sought to determine the factors affecting uterine scar formation and predict the risk of scar rupture by performing second look laparoscopy after laparoscopic myomectomy. Of the 628 wounds observed from second look laparoscopy, 9.2\% had a scarred uterus and this was significantly related to complete myometrial penetration and submucosal myoma. While none of the patients suffered from a uterine rupture in the series, it suggested that second look laparoscopy could potentially be utilized to predict the risk of uterine rupture. ${ }^{14}$ Several studies have also suggested the use of ultrasound imaging in evaluating myometrial healing to determine its risk of rupture. A recent cohort prospective study by Tinelli followed patients after laparoscopic myomectomy with regular 2D ultrasound and Doppler velocimetry to evaluate uterine perfusion, haematoma formation, scar area and pressure and resistance index of the uterine arteries etc. ${ }^{15}$ These are risk factors for poor myometrial healing and may effectively aid in the identification of "high risk" scars.

\section{Method of repair}

There has also been much debate about the type of suture repair implicating risk of uterine rupture. While some clinicians attribute single layer closure with a doubled risk of uterine rupture, this is an issue that has been widely debated. ${ }^{16}$ Interestingly, in Gambacorti-Passerini's systematic review, it was even shown that $71.4 \%$ of uterine rupture occurred in patients with a double-layered repair in contrast to $28.6 \%$ in those with a single layered repair. ${ }^{3}$ Tian's retrospective study on pregnancy after myomectomy also revealed that $50 \%$ of uterine dehiscence happened in cases with double-layer closure. ${ }^{13}$ These suggest that rather than the absolute number of layers to suture, the best suturing technique is one that respects the basic principles of good tissue repair - full depth of the edges must be taken, minimal tension, and prevention of haematoma. ${ }^{5,13}$ In the case when these principles cannot be achieved through laparoscopy, one should consider the use of laparoscopic-assisted myomectomy (LAM). ${ }^{5}$ LAM was first described in 1994 by Nezhat as an alternative to laparotomy and laparoscopic myomectomy. ${ }^{17}$ Seidman subsequently compared the outcomes of LAM against conventional approaches. LAM was performed for large myomas requiring extensive morcellation or deep intramural myomas requiring uterine repair. A cockscrew manipulator is inserted into the myoma, lifting it against the midline suprapublic puncture. The $5 \mathrm{~mm}$ puncture is then extended transversely to 4 to $5 \mathrm{~cm}$, facilitating rapid removal of the myoma and reconstruction of the uterine 
defect by sutures. The study found LAM to be a favourable alternative to laparoscopic myomectomy especially for large or deep intramural myomas due to reduced operative time and access to meticulous suturing yet reducing the risk of adhesion formation from that of laparotomy myomectomy. ${ }^{18}$

\section{Electrocoagulation}

Electrocoagulation should be minimized, if not avoided, in laparoscopic myomectomy. While electrocoagulation is an effective method for haemostasis, it results in devascularization of myometrium causing inflammation and necrosis, impairing wound healing. GambacortiPasserini's systematic review revealed that use of electrocautery was higher in the group with uterine rupture and in all 7 cases of uterine rupture, electrocautery was used. ${ }^{3}$ This is not only restricted to uterine incisions but was seen even in a case of a pedunculated subserosal posterior uterine wall fibroid with no uterine incision. ${ }^{19}$ It is therefore recommended that electrocoagulation be kept to a minimum. ${ }^{5}$ In addition, when a pedunculated fibroid is removed solely by electrocautery, the implantation surface should be reinforced with a suture if it is more than $1 \mathrm{~cm} .^{3,5}$

Interestingly, in studied case, the uterine rupture was complicated by spontaneous haemothorax. Haemothorax is defined as pleural fluid with a haematocrit greater than $50 \%$ of the patient's blood haemocrit level. Common causes are thoracic trauma or iatrogenic. A small proportion are however spontaneous, and these include vascular events (such as aortic dissection or aneurysm, arteriovenous malformation), coagulopathy, malignancy, endometriosis (Catamenial haemothorax) etc. ${ }^{20} \mathrm{~A}$ review of current literature revealed little mention regarding the association of haemothorax with haemoperitoneum. Vaughan et al reports a case of spontaneous haemothorax secondary to haemoperitoneum after a caesarean section. $^{21}$ This was attributed to diaphragmatic fenestration along with raised intra-abdominal pressure in pregnancy. Another case report by May also described haemothorax from haemoperitoneum secondary to porous diaphragm syndrome. ${ }^{22}$ Although rare, haemothorax may occur in patients with haemoperitoneum and clinicians should remain vigilant especially when there is evidence of respiratory compromise as it is a potentially lifethreatening condition with rapid ventilatory collapse.

\section{CONCLUSION}

While uterine rupture is a rare complication following laparoscopic myomectomy, it certainly has serious maternal and fetal morbidities and mortality. This case reports the worrying features of an early antepartum rupture presenting with atypical symptomatology. Therefore, when pregnant patients present with abdominal pain or haemodynamic instability, it is imperative to consider uterine rupture as a possible cause and perform timely intervention. Pregnant women with a past history of laparoscopic myomectomy should be considered high risk and counseled about the risk of rupture and an extensive discussion about mode of delivery undertaken. Future studies could also look into generating selection criterias to stratify patients at higher risk of uterine rupture.

\section{Funding: No funding sources \\ Conflict of interest: None declared \\ Ethical approval: Not required}

\section{REFERENCES}

1. Vilos GA, Allaire C, Laberge PY, Leyland N, Vilos AG, Murji A, et al. The management of uterine leiomyomas. J Obstet Gynaecol Can. 2015;37(2):157-81.

2. Li TC, Mortimer R, Cooke ID. Myomectomy: a retrospective study to examine reproductive performance before and after surgery. Hum Reprod. 1999 Jul;14(7):1735-40.

3. Gambacorti-Passerini Z, Gimovsky AC, Locatelli A, Berghella V. Trial of labor after myomectomy and uterine rupture: a systematic review. Acta Obstet Gynecol Scand. 2016;95:724-34.

4. Royal College of Obstetricians and Gynaecologists (RCOG). Birth after previous caesarean birth. Greentop guideline no. 45. 2015. Available at: https://www.rcog.org.uk/globalassets/documents/gui delines/gtg_45.pdf. Accessed 22 Aug 2016.

5. Dubuisson JB, Fauconnier A. Laproscopic myomectomy. In: Jacques Donnez. Atlas of operative laparoscopy and hysteroscopy. $3^{\text {rd }}$ ed. Informa UK Ltd; 2007. 227-238.

6. Bulletti C, Polli V, Negrini V, Giacomucci E, Flamigni C. Adhesion formation after laparoscopic myomectomy. J Am Assoc Gynecol Laparosc. 1996;3,533-6.

7. Kiseli M, Artas H, Armagan F, Dogan Z. Spontaneous Rupture of Uterus in Mid-trimester pregnancy due to increased uterine pressure with previous laparoscopic myomectomy. Int $\mathbf{J}$ Fertl Steril. 2013;7(3):239-42.

8. Sutton C, Standen P, Acton J, Griffin C. Spontaneous uterine rupture in a preterm pregnancy following myomectomy. Case Rep Obstet Gynecol 2016;2016.

9. Djaković I, Sabolović Rudman S, Djaković Ž, Košec V. Uterine Rupture Following Myomectomy in Third Trimester. Acta Clinica Croatica. 2015;54.4:521-3.

10. Song SY, Yoo HJ, Kang BH, Ko YB, Lee KH, Lee $\mathrm{M}$. Two pregnancy cases of uterine scar dehiscence after laparoscopic myomectomy. Obstet Gynecol Sci. 2015;58.6:518-21.

11. Kacperczyk J, Bartnik P, Romejko-Wolniewicz E, Dobrowolska-Redo A. Postmyomectomic Uterine Rupture Despite Cesarean Section. Anticancer Res. 2016;36(3):1011-3.

12. Bernardi TS, Radosa MP, Weisheit A, Diebolder H, Schneider U, Schleussner E, et al. Laparoscopic 
myomectomy: a 6-year follow-up single-center cohort analysis of fertility and obstetric outcome measures. Arch Gynecol Obstet. 2014;290(1):87-91.

13. Tian YC, Long TF, Dai YM. Pregnancy outcomes following different surgical approaches of myomectomy. J Obst Gynaecol Res. 2015;41(3):3507.

14. Kumakiri J, Kikuchi I, Kitade M, Kumakiri Y, Kuroda K, Matsuoka S, et al. Evaluation of factors contributing to uterine scar formation after laparoscopic myomectomy. Acta Obstet Gynecol Scand. 2010;89(8):1078-83.

15. Tinelli A, Hurst BS, Mettler L, Tsin DA, Pellegrino $\mathrm{M}$, Nicolardi $\mathrm{G}$, et al. Ultrasound evaluation of uterine healing after laparoscopic intracapsular myomectomy: an observational study. Hum Reprod 2012;27(9):2664-70.

16. Bujold E, Goyet M, Marcoux S, Brassard N, Cormier $\mathrm{B}$, Hamilton E, et al. The role of uterine closure in the risk of uterine rupture. Obstet Gynecol 2010;116(1):43-50.

17. Nezhat C, Nezhat F, Bess O, Nezhat CH, Mashiach R. Laparoscopically assisted myomectomy: a report of a new technique in 57 cases. Int $\mathrm{J}$ Fertil Menopausal Stud 1993;39(1):39-44.

18. Seidman DS, Nezhat CH, Nezhat F, Nezhat C. The role of laparoscopic-assisted myomectomy (LAM).
JSLS: J Society of Laparoendoscopic Surg 2001;5(4):299.

19. Hasbargen U, Summerer-Moustaki M, Hillemanns P, Scheidler J, Kimmig R, Hepp H. Uterine dehiscence in a nullipara, diagnosed by MRI, following use of unipolar electrocautery during laparoscopic myomectomy: case report. Hum Reprod. 2002;17(8):2180-2.

20. Broderick, Stephen R. Hemothorax: etiology, diagnosis, and management. Thoracic Surg Clin. 2013;23(1):89-96.

21. Vaughan P, Hooper PJ, Duffy JP. Spontaneous hemothorax after caesarian section: an unusual manifestation of diaphragmatic fenestrations. Ann Thoracic Surg 2005;80(4):1517-9.

22. May J, Ades A. Porous diaphragm syndrome: haemothorax secondary to haemoperitoneum following laparoscopic hysterectomy. BMJ Case Rep. 2013: bcr2013201088.

Cite this article as: Cheong CPS, Tan AWK, Tan $\mathrm{LK}, \mathrm{Yu}$ SL. Unusual presentation of uterine rupture following laparoscopic myomectomy: a case report and literature review. Int J Reprod Contracept Obstet Gynecol 2018;7:3868-72. 